
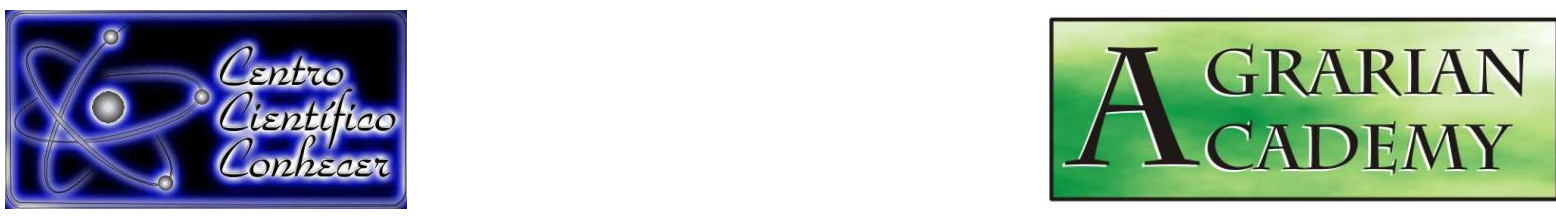

\title{
PERDAS QUANTITATIVAS NA COLHEITA MECANIZADA DE MILHO SAFRINHA NA REGIÃO NORTE DE MATO GROSSO
}

Taniele Carvalho de Oliveira ${ }^{1}$, Zulema Netto Figueiredo ${ }^{2}$, Henrique Guimarães de Favare $^{3}$, Jaqueline Gomes Troui ${ }^{4}$, Rouverson Pereira Silva ${ }^{5}$

1. Mestranda em Genética e Melhoramento de Plantas, Universidade do Estado de Mato Grosso (UNEMAT), Cáceres - MT, Brasil, (tani.ele@hotmail.com).

2. Profa Dra da Universidade do Estado de Mato Grosso (UNEMAT), Cáceres-MT, Brasil.

3. Mestrando em Ciência Florestais e Ambientais da Universidade do Federal de Mato Grosso (UFMT), Cuiabá-MT, Brasil.

4. Graduanda em Agronomia da Universidade do Estado de Mato Grosso (UNEMAT), Cáceres-MT, Brasil.

5. Prof. Dr. da Universidade Estadual Paulista Júlio de Mesquita Filho (UNESP), Jaboticabal-SP, Brasil.

Recebido em: 05/12/2014 - Aprovado em: 14/12/2014 - Publicado em: 15/12/2014

\section{RESUMO}

O presente trabalho teve o objetivo de quantificar as perdas durante a colheita mecanizada de milho safrinha em propriedades rurais de Sinop-MT. Foram avaliadas seis propriedades rurais em julho/2012, as coletas foram realizadas em duas etapas sendo na primeira coleta em quatro propriedades e a segunda em duas propriedades devido ao encerramento do período de colheita da safrinha. Utilizou-se o delineamento de blocos casualizado (DBC), com quatro repetições, as avaliações in loco foram realizadas durante a operação de colheita: perdas de pré-colheita, perdas da plataforma de corte, perdas do sistema de trilha e limpeza e perdas totais (mecanismos internos), utilizando uma armação retangular de acordo com a largura da plataforma de corte, totalizando área de $2 \mathrm{~m}^{2}$ e de $1 \mathrm{~m}^{2}$ para avaliação de perdas pré-colheita. Os dados obtidos foram submetidos à análise de variância e a comparação das médias pelo teste de Tukey, ao nível de $5 \%$ de probabilidade, com auxílio do programa estatístico Sisvar. As perdas ocasionadas durante a colheita de milho foram baixas, indicando que as regulagens das colhedoras e o treinamento do operador podem ter contribuído para perdas em níveis aceitáveis. A velocidade de deslocamento e a umidade dos grãos não afetaram as perdas causadas pela colhedora.

PALAVRAS-CHAVE: colhedoras, velocidade, Zea mays $L$.

\section{CORN HARVESTING LOSSES IN NORTH REGION OF MATO GROSSO STATE}

\begin{abstract}
The aim of this work was to quantify of the corn harvest combine losses in six farms of Sinop region, Mato Grosso State, Brazil. Was evaluated six farms in 2012 July and data collecting was in two steps with four farms in first time and two farms in second steps because the end of corn harvesting season. The experimental design was a randomized block design with 4 replications, collected data and evaluating was during harvest operation: Pre-harvesting losses, harvesting losses in combine
\end{abstract}


caused by combine header and combine internal system like concave, cylinder and rotor speed and total harvest losses, for this was used one rectangular rope frame with length was width of combine header, in total area of $2 \mathrm{~m}^{2}$ and used $1 \mathrm{~m}^{2}$ for collected Pre-harvesting losses. The data was evaluated by variance analyses and compared of average by Tukey test, with $5 \%$ of probability using statistic computer program Sisvar. The harvest combine losses were low, indicating that adjustment of combines and operator trainings can be contributed of acceptable losses level. The speed ground and grain moisture not affected of combine losses.

KEYWORDS: Zea mays L., combine, ground speed

\section{INTRODUÇÃO}

O milho (Zea mays L.) é uma das principais espécies cultivadas no Brasil e no mundo e desempenha um importante papel na agricultura, devido a sua adaptabilidade aos diferentes climas e solos, além de ser o principal grão presente alimentação animal e de ser uma das fontes básicas na alimentação humana, apresentando um importante papel socioeconômico (VENEGAS et al., 2012).

Os principais produtores mundiais de milho atualmente são os Estados Unidos, China, Brasil e Argentina (FAOSTAT, 2012). No Brasil os estados com maior produção de milho na safra 2011/12 foram: Mato Grosso, com 12.382,6 mil t, Paraná com 9.605,8 mil t e Mato Grosso do Sul com 4.446,0 mil t, colhidos em uma área de plantio de 2.569, 2.001 e 1.140 mil hectares respectivamente (CONAB, 2012).

A colheita mecanizada de milho é a última etapa do processo produtivo, devendo ter maiores cuidados ao conduzi-la, pois quando executada sem o emprego de alguns critérios podem acarretar grandes perdas, aumentando o custo de produção e, consequentemente, redução na rentabilidade do produtor (BERTONHA et al. 2012).

As perdas ocasionadas durante a colheita pode ser influenciada por diversos fatores como o preparo do solo, época incorreta de semeadura, espaçamento e densidade, cultivares não adaptados, ocorrência de plantas daninhas, atraso na colheita, umidade inadequada, falta de monitoramento das perdas e má regulagem e operação da colhedora. De acordo com MESQUITA et al. (1998) um nível tolerável de perda para a cultura do milho está em torno de $1,5 \mathrm{sc} / \mathrm{ha}$, dentre as perdas totais de grãos, geralmente $80 \%$ das perdas estão na plataforma de corte das colhedoras, outras perdas devido ao sistema de trilha.

De acordo com MAGALHÃES et al. (2009) as perdas na colheita mecanizada de milho são influenciadas pela velocidade da colhedora e as perdas no sistema de limpeza apresentaram maior contribuição para as perdas totais. SILVA et al. (2004) avaliando as perdas de grãos da cultura de milho em lavouras das regiões do Triângulo Mineiro e Alto Paranaíba, constataram que máquinas com sistema de trilha axial apresentaram menores perdas do que àquelas com sistema de trilha radial.

SOUZA et al. (2006) estimando as perdas de grãos ocasionadas durante a colheita do milho, cultivado em áreas de agricultura familiar da Zona da Mata Mineira, não observaram influência da velocidade de deslocamento e da rotação do cilindro trilhador sobre as perdas na plataforma de corte e no sistema de trilha. CORTEZ et al. (2009) estudaram a influência dos sistemas de adubação (em présemeadura e na semeadura) e dos consórcios de culturas intercalares na colheita mecanizada de milho em sistema plantio direto e observaram que as perdas na colheita não foram afetadas pelos sistemas de adubação e consórcios avaliados.

Objetivou-se com o presente trabalho quantificar as perdas durante a colheita mecanizada de milho safrinha em propriedades rurais de Sinop-MT. 


\section{MATERIAL E MÉTODOS}

O trabalho foi desenvolvido na região produtora de Sinop (Norte) em Mato Grosso, dentro da safra de milho safrinha 2012, com uma amostra de seis propriedades rurais (Quadro 1). A escolha da região produtora e das propriedades foi da Associação dos Produtores de Soja e Milho de Mato Grosso - APROSOJA, na parceria da Universidade do Estado de Mato Grosso - UNEMAT e outras entidades locais.

QUADRO 1. Dados das propriedades analisadas.

$\begin{array}{cc}\text { Denominação } & \text { Máquina } \\ \text { Fazenda 01 } & \text { JD } 1550 \\ \text { Fazenda 02 } & \text { TC 59 } \\ \text { Fazenda 03 } & \text { TC 59 } \\ \text { Fazenda 04 } & \text { MF 9790 } \\ \text { Fazenda 05 } & \text { 2MF 34 } \\ \text { Fazenda 06 } & \text { 2TC 59 }\end{array}$

As coletas foram realizadas em julho/2012 em duas etapas sendo a primeira coleta em quatro propriedades e a segunda em duas propriedades devido ao encerramento da colheita do milho safrinha na região e para efeitos metodológicos será adotado somente a denominação em números que correspondam a sequência das visitas de coleta de dados.

Utilizou-se o delineamento de blocos casualizado (DBC), com quatro repetições, com parcelas de 50 metros de comprimento. Foi utilizada uma armação retangular de acordo com a largura da plataforma de corte, totalizando área de $2 \mathrm{~m}^{2} \mathrm{e}$ de $1 \mathrm{~m}^{2}$ para avaliação de perdas pré-colheita, conforme metodologia descrita por MESQUITA et al. (2011) e PORTELLA (2000). (Figura 1).

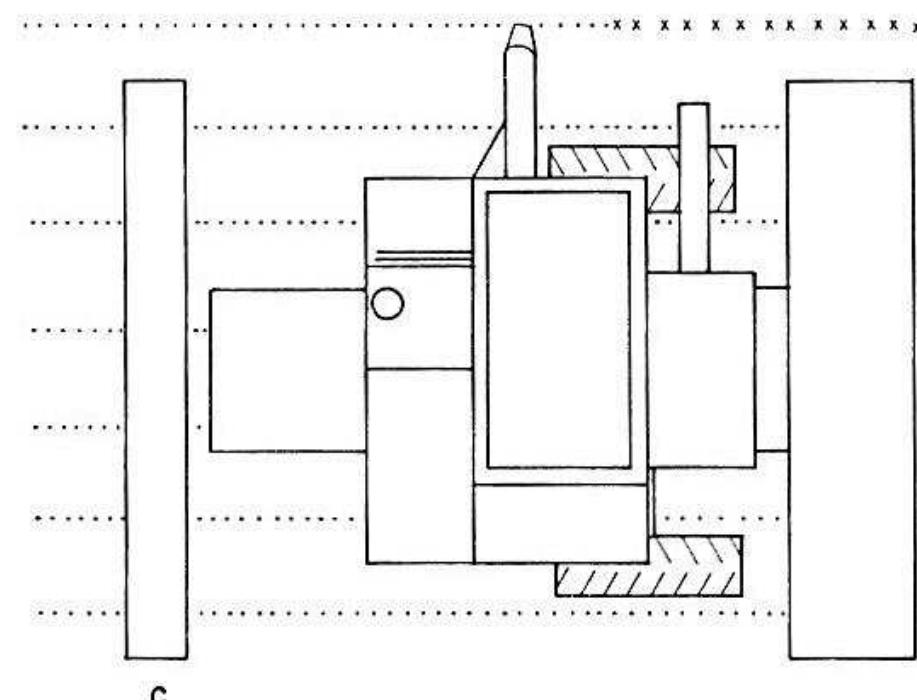
A. Perdas pré-colheita
B. Perdas da plataforma
C. Perdas do mecanismo interno

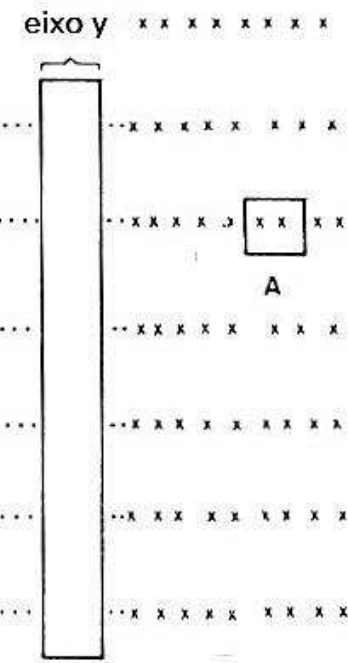

Fonte: Adaptado de MESQUITA et al. 2011; PORTELLA, 2000.

FIGURA 1. Esquema de contagem de perdas. 
As características avaliadas forma:

a) Perdas em pré-colheita: realizada antes de iniciar a colheita no talhão especifico, com medições em locais distintos, colocando uma armação de $1 \mathrm{~m}^{2}$ no sentido transversal ao plantio, coletando os grãos e as espigas caídas dentro da armação.

b) Perdas na plataforma de corte: a colhedora estando em funcionamento dentro da parcela, depois de parada, jogou toda a palha para fora da máquina retrocedeu a uma distância igual ao seu comprimento, onde foi colocada a armação na frente da colhedora e coletados os grãos, inclusive os que permaneceram nas espigas. Para encontrar as perdas na plataforma de corte, foi tomado este número e subtraído do resultado das perdas de grãos em pré-colheita.

c) Perdas nos mecanismos internos: foi colocado a armação depois da passagem da colhedora, coletado os grãos, para se obter o resultado subtraiu a perda de grãos em pré-colheita, bem como as da plataforma.

d) Perda total da colhedora: resultado das perdas obtidas na plataforma de corte e das obtidas na trilha, nos saca-palha e nas peneiras.

Devido às condições físicas de cada propriedade, foi avaliado apenas na Faz 05 a distribuição da palhada após a passagem da colhedora, utilizando da mesma armação de coleta, entretanto o barbante utilizado na armação foi demarcado de 10 em $10 \mathrm{~cm}$ colocado para leitura onde se encontrava ou não palha.

As médias das parcelas foram convertidas em $\mathrm{kg} \mathrm{ha}^{-1}$, a umidade dos grãos durante a colheita variou entre 13 e $15 \%$, umidade considerada ideal, mas que pode interferir nas perdas da colhedora.

A maioria das máquinas era do ano de 2000 e 2001 e estavam trabalhando com plataformas novas, como no caso da Faz 02 e Faz 03, cujas plataformas são do ano 2008 e 2012. A Faz 01 foi o caso contrário cuja máquina do ano 2001 estava trabalhando com plataforma 2000. A máquina mais nova foi da Faz. 04 MF 9790 do ano 2011 e plataforma com largura de 11 metros (Quadro 2).

QUADRO 2. Dados das máquinas avaliadas.

\begin{tabular}{ccccc}
\hline Fazenda & $\begin{array}{c}\text { Modelo da } \\
\text { máquina }\end{array}$ & Ano da máquina & $\begin{array}{c}\text { Velocidade } \\
\text { (km h } \mathbf{r p m})\end{array}$ & $\begin{array}{c}\text { Sistema } \\
\text { de trilha }\end{array}$ \\
\hline Faz 01 & JD 1550 & 2001 Plataforma 2000 & 8,0 & Radial \\
Faz 02 & TC 59 & 2000 Plataforma 2008 & 7,0 & Radial \\
Faz 03 & TC 59 & 1998 Plataforma 2012 & 7,0 & Radial \\
Faz 04 & MF 9790 & 2011 & 7,0 & Axial \\
Faz 05 & MF 34 & 2004 & 7,0 & Radial \\
Faz 06 & TC 59 & 2003 & 7,5 & Radial \\
& TC 59 & 2004 & 7,5 & Radial \\
\hline
\end{tabular}

Os dados obtidos foram submetidos à análise de variância pelo teste $\mathrm{F}$ e a comparação de médias, pelo teste de Tukey, ao nível de $5 \%$ de probabilidade, com auxílio do programa estatístico Sisvar (FERREIRA, 2011).

\section{RESULTADOS E DISCUSSÃO}

Na tabela 1, encontra-se a síntese da análise de variância e teste de média das perdas ocasionadas na plataforma, mecanismos internos e totais. Em relação às perdas referentes à plataforma de corte foram baixas e não significativas (Tabela 3). Esse resultado é contrário ao especificado por PORTELLA (2000) que cita ser na plataforma de colheita onde ocorrem as maiores perdas, pois podem ocorrer perdas 
por espigas para foram da plataforma e grãos debulhados devido ao impacto da colhedora na planta.

TABELA 1. Síntese da análise de variância e teste de médias para as variáveis perdas provocadas pela plataforma de corte, mecanismos internos e perdas totais provocadas pela colhedora. Sinop, Mato Grosso, 2012.

\begin{tabular}{|c|c|c|c|}
\hline \multirow[t]{2}{*}{ Fazenda } & $\begin{array}{l}\text { Perdas da } \\
\text { plataforma }\end{array}$ & $\begin{array}{c}\text { Perdas dos } \\
\text { mecanismos internos }\end{array}$ & Perdas Totais \\
\hline & \multicolumn{3}{|c|}{ - } \\
\hline Faz 01 & $12,09 \mathrm{a}$ & $39,98 \mathrm{~b}$ & $52,08 \quad b$ \\
\hline Faz 02 & $12,43 \mathrm{a}$ & $78,06 \mathrm{ab}$ & $90,50 a b$ \\
\hline Faz 03 & $9,74 \mathrm{a}$ & $150,19 a$ & 159,94 a \\
\hline Faz 04 & 28,22 a & $55,55 \mathrm{~b}$ & $83,77 \mathrm{ab}$ \\
\hline Faz 05 & $9,40 \mathrm{a}$ & $5,70 \mathrm{~b}$ & $15,12 b$ \\
\hline Faz 06 & $13,10 \mathrm{a}$ & $15,20 \mathrm{~b}$ & $27,88 \quad b$ \\
\hline Teste F & $0,57^{\mathrm{ns}}$ & $6,98^{* *}$ & $7,10^{* *}$ \\
\hline $\mathrm{CV}(\%)$ & 65,00 & 69,20 & 55,10 \\
\hline
\end{tabular}

Médias seguidas de mesma letra nas colunas indicam que os resultados não diferiram entre si, pelo teste de Tukey a $1 \%$.

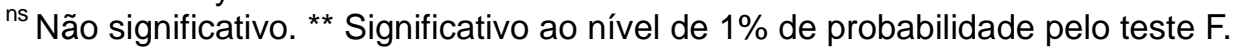

As perdas de grãos referentes aos mecanismos internos e totais apresentaram diferenças significativas pelo teste $F$, as maiores perdas encontradas foram da Faz 03, acima do nível máximo aceitável de 1,5 sacos/ha. Os resultados encontrados neste trabalho diferem de LOUREIRO et al. (2012) avaliando as perdas quantitativas ocorridas na colheita mecanizada do milho cultivado em espaçamentos reduzido e convencional, observaram perdas superiores a 1,5 sacos/ha para perdas na plataforma e mecanismos internos.

De maneira geral para as perdas dos mecanismos internos e totais foram baixos. As perdas encontradas na Faz 03 podem ter sido ocasionadas pela idade da colhedora. SILVA et al. (2004) ressaltam que máquinas com idade entre zero e cinco anos apresentaram menores valores de perdas para a cultura de milho quando comparadas àquelas com mais de seis anos de idade. Entretanto, MAGALHÃES et al. (2009) afirmam que colhedoras mais velhas do ano 2001/02, podem apresentar resultados melhores que uma colhedora de 2012, indicando que regulagens, manutenção, e cuidados com operação são mais eficientes para evitar perdas do que o ano de fabricação do maquinário, que também foi comentado por MESQUITA et al. (2001).

De acordo com a classificação de PIMENTEL GOMES (2009), os valores do coeficiente de variação (CV) para as características plataforma de corte, mecanismos internos e perdas totais foram altos (>20\%), podendo ser justificado pela variabilidade encontrada na determinação de perdas no campo. Entretanto estão dentro do limite encontrado por outros autores, CORTEZ et al. (2009) encontraram coeficiente de variação alto $(83,9 \%)$ para a variável perdas na colheita de milho, explicando que os altos valores de coeficiente de variação podem estar associados à irregularidade das espigas e ao fluxo de material que entra na colhedora.

A Figura 2 representa graficamente as perdas durante as avaliações da colheita. As perdas de grãos antes da colheita foram inexpressivas, não houve perdas significativas indicando que a cultivar utilizada adaptou-se ao clima e solo da região. 


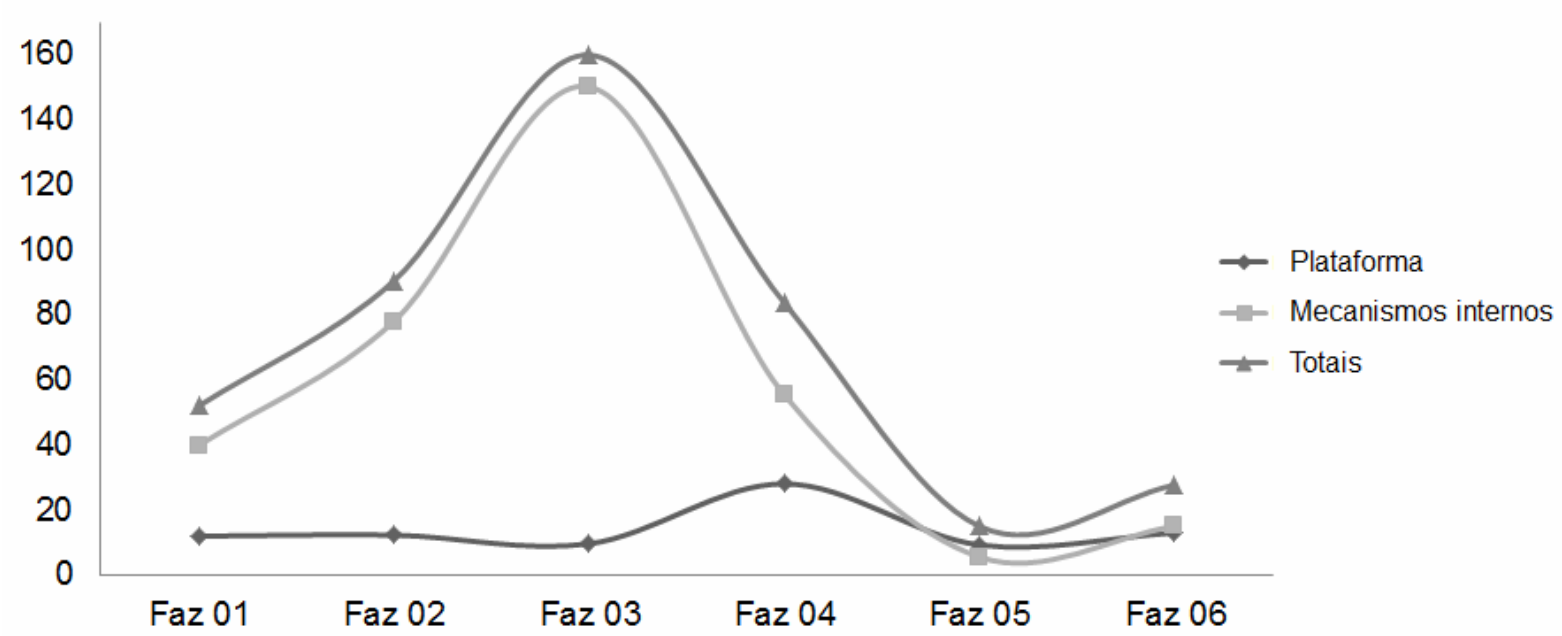

FIGURA 2. Perdas em $\mathrm{kg} \mathrm{ha}^{-1}$ referente as perdas da plataforma de corte, mecanismos internos e perdas totais. Sinop, Mato Grosso, 2012.

Efeito que pode ser devido a fatores como boa manutenção de máquinas, fatores relacionados à cultura como a umidade no momento da colheita, já que todos apresentaram teor de umidade entre 12 e 14\% de umidade dos grãos. Dados como os encontrados por PORTELLA (2000) em que avaliou a influência do ponto de colheita (umidade) nas perdas de grãos utilizando uma colhedora MF 3640 ano 1989. Encontrou os menores índices de perdas na plataforma $(0,60 \%)$ e nos mecanismos internos $(0,29 \%)$, na colheita com o milho a $15 \%$ de umidade, comparado com 18, 25 e 35\% de umidade. TABILE et al. (2008) avaliaram perdas na colheita do milho em função da rotação do cilindro trilhador e umidade dos grãos, não encontraram influência das variáveis sobre as perdas, a perda da plataforma não foi influenciada pela umidade.

Segundo SGARBI (2006) na medida em que os grãos vão secando na lavoura, melhora o desempenho da colhedora, tanto na plataforma quanto nos mecanismos internos (trilha e separação). Segundo HOLTZ \& REIS (2012) para a cultura da soja metade das perdas pode ser evitada ou monitorada para valores aceitáveis e comenta que alguns produtores têm obtido perdas muito próximas de valores considerados excelentes aproximando-se de $10 \mathrm{~kg} \mathrm{ha}^{-1}$. Assim como este trabalho comprova que algumas propriedades obtiveram resultados excelentes.

Quanto ao sistema de trilha, somente uma máquina (Faz 04) do ano 2011, apresentava sistema axial o que segundo autores como CAMPOS et al. (2005) que encontraram diferenças significativas para perdas de grãos com colhedoras de fluxo axial sendo menores que as colhedoras radiais (com cilindro e côncavo), e segundo COSTA et al. (2002) as colhedoras axiais possuem maior capacidade de colheita e apresentam redução de danos mecânicos às sementes, ainda que apresentem um custo de aquisição elevado para os produtores brasileiros. Quanto a regulagem do sistema de trilha a rotação do cilindro esteve entre $600 \mathrm{rpm}$ e abertura de $3 \mathrm{amm}$.

Em relação às velocidades de deslocamento LOUREIRO et al. (2012) ressaltam que menores velocidades provocarem vibração na planta de milho que pode fazer com que a espiga se desprenda da planta antecipadamente e acabe caindo fora da plataforma de colheita, ocasionando as perdas por espigas. À medida que a velocidade cresce, as perdas diminuem até chegar a um ponto ótimo. Depois de um determinado ponto, o acréscimo de velocidade de deslocamento na máquina 
provoca impacto mais forte sobre a planta, ocasionando o que essa seja arremessada fora da plataforma de colheita. Apesar de todas as propriedades utilizarem velocidades em torno de $7,5 \mathrm{~km} / \mathrm{h}$ provavelmente a velocidade e outros fatores podem ter contribuído para a baixa perda na plataforma.

A característica de distribuição de palha (Figura 3) demonstrou visualmente boa cobertura de palha pela colhedora, nas quatro repetições realizadas. Estes resultados diferem de CHIODEROLI et al. (2012) onde determinaram as perdas quantitativas, distribuição de palha e características operacionais da colhedora por meio do controle estatístico de processo, estes autores observaram que a porcentagem de distribuição da cobertura vegetal manteve-se fora de controle.

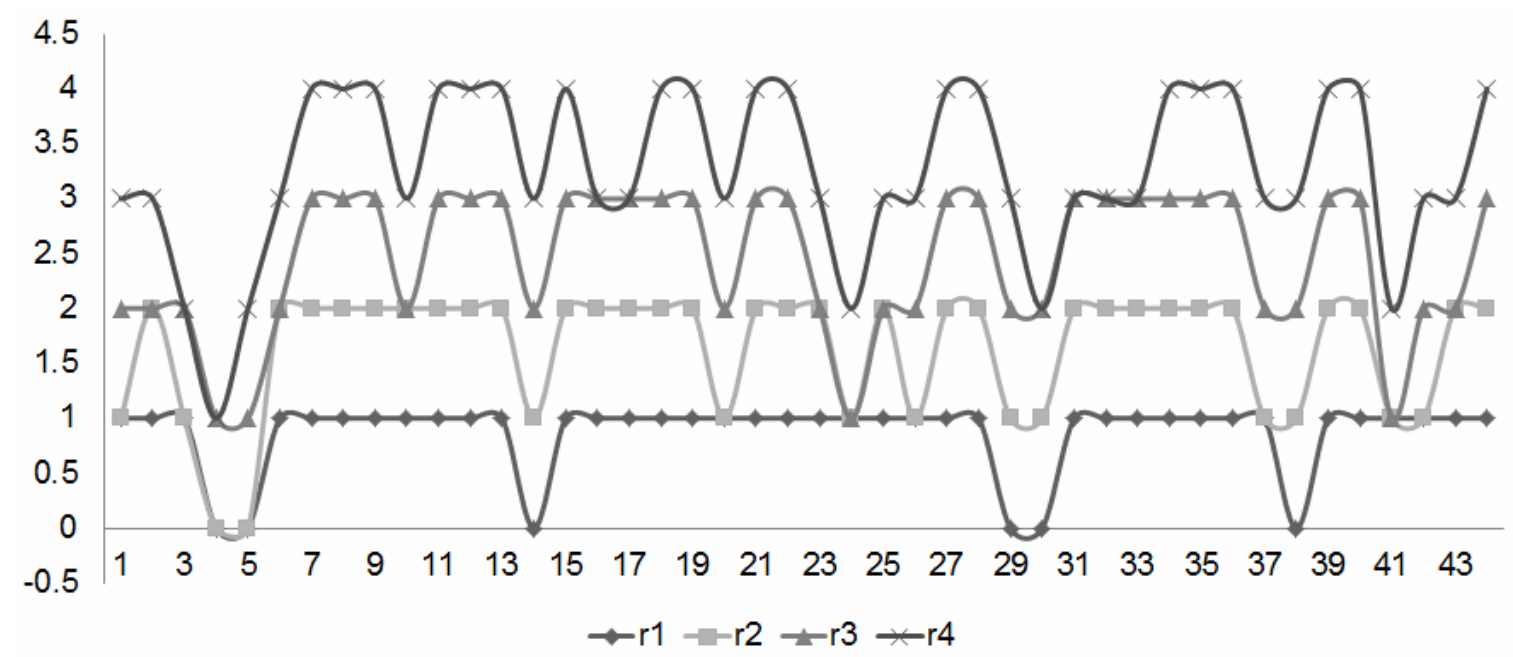

FIGURA 3. Distribuição de palhada promovido pela colhedora na Faz 05. Sinop, Mato Grosso, 2012.

\section{CONCLUSÃO}

As perdas ocasionadas durante a colheita de milho foram baixas, indicando que as regulagens das colhedoras e o treinamento do operador podem ter contribuído para perdas em níveis aceitáveis. A velocidade de deslocamento e a umidade dos grãos não afetaram a colheita de milho.

\section{REFERÊNCIAS}

BERTONHA, R.S.; SILVA, R.P.; BARROZO, L.M.; CAVICHIOLI, F.A.; CASSIA, M.T. Perdas e desempenho de sementes de milho em dois sistemas de preparo do solo e velocidades de deslocamento da colhedora. Revista Brasileira de Milho e Sorgo, v.11, n.3, p. 243-253, 2012.

CAMPOS, M.A.O.; SILVA, R.P.; CARVALHO, A.F.; MESQUITA, H.C.B.; ZABANI, S. Perdas na colheita mecanizada de soja no Estado de Minas Gerais. Engenharia Agrícola, v.25, n.1, p.207-213, 2005.

CHIODEROLI, C.A.; SILVA, R.P.; NORONHA, R.H.F.; CASSIA, M.T.; SANTOS,E.P. Perdas de grãos e distribuição de palha na colheita mecanizada de soja. Bragantia, v.71, n.1, p.112-121, 2012. 
CONAB. Companhia Nacional de Abastecimento. Acompanhamento de safra brasileira: grãos, nono levantamento, junho 2012. Disponível em: http://www.conab.gov.br/OlalaCMS/uploads/arquivos/12_06_12_16_15_32_boletim_ portugues_junho_2012.pdf. 2012. Acesso em: 20 de janeiro de $201 \overline{3}$.

COSTA, N.P.; MESQUITA, C.M.; MAURINA, A.C.; FRANÇA-NETO, J.B.; PEREIRA, J.E.; KRZYZANWSKI, F.C.; HENNING, A.A. Avaliação da qualidade de sementes e grãos de soja provenientes da colheita mecanizada, em diferentes regiões do Brasil. Engenharia Agrícola, v.22, n.2, p.211-19, 2002.

CORTEZ, J.W.; FURLANI, C.E.A.; SILVA, R.P. Sistemas de adubação e Consórcio de culturas intercalares e seus efeitos nas variáveis de colheita da cultura do milho Engenharia Agrícola, v.29, n.2, p.277-287, 2009.

FAOSTAT - Food and Agriculture Organization - FAO, 2012 - Disponível em: http://www.fao.org.br. 2012. Acesso em: 13 de maio de 2013.

FERREIRA, D.F. Sisvar: a computer statistical analysis system. Ciência e Agrotecnologia, v.35, n.6, p.1039-1042, 2011.

HOLTZ, V.; REIS, E.F. Colhedoras - Detalhes que definem. Cultivar máquinas, v.11, n.117, p.18-22, 2012.

LOUREIRO, D.R.; FERNANDES, H.C.; TEIXEIRA, M.M.; LEITE, D.M.; COSTA, M.M. Perdas quantitativas na colheita mecanizada do milho cultivado em espaçamento reduzido e convencional. Semina, v.33, n.2, p.565-574. 2012.

MAGALHÃES, S.C.; OLIVEIRA, B.C.; TOLEDO, A.; TABILE, R.A.; SILVA, R.P. Perdas quantitativas na colheita mecanizada de soja em diferentes condições operacionais de duas colhedoras. Bioscience Journal, v.25, n.5, p.43-48, 2009.

MESQUITA, C.M.; COSTA, N.P.; MANTOVANI, E.C.; ANDRADE, J.G.M.; FRANÇA NETO, J.B.; SILVA, J.G.; FONSECA, J.R.; PORTUGAL, F.A.F.; GUIMARÃES SOBRINHO, J.B. Manual do produtor: Como evitar desperdícios nas colheitas da soja, do milho e do arroz. Londrina: EMBRAPA-CNPSo, 1998. 32p.

MESQUITA, C.M.; COSTA, N.P. (In memorian); MANTOVANI, E.C.; ANDRADE, J.G. M.; NETO, J.B.F.; SILVA, J.G.; FONSECA, J.R.; SOBRINHO, J.B.G. Monitoramento das perdas de grãos na colheita de soja. Londrina: Embrapa Soja, 2011. 14p.

MESQUITA, C.M.; COSTA, N.P.; PEREIRA, J.E.; MAURINA, A.C.; ANDRADE, J.G.M. Caracterização da colheita mecanizada da soja no Paraná. Engenharia Agrícola, v.21, n.2, p.197-205, 2001.

PIMENTEL-GOMES, F. Curso de estatística experimental. 15 FEALQ, 2009, 451p.

PORTELLA, J.A. Colheita de grãos mecanizada: implementos, manutenção e regulagem. Viçosa: Aprenda Fácil, 2000. 190 p. 
SGARBI, V.P. Perdas na colheita de milho (Zea mays L.) em função da rotação do cilindro trilhador e umidades dos grãos. 2006. 33p. Monografia (Graduação em Agronomia) - Faculdade de Ciências Agrárias e Veterinárias, Jaboticabal, SP.

SILVA, R.P.; CAMPOS, M.A.O.; MESQUITA, H.C.B.; ZABANI, S. Perdas na colheita mecanizada de milho no Triângulo Mineiro e Alto Paranaíba-MG. FAZU em Revista, n.1, p.3-10, 2004.

SOUZA, C.M.A.; RAFULL, L.Z.L.; REIS, E.F.; ALVES SOBRINHO, T. Perdas na colheita mecanizada de milho em agricultura familiar da zona da mata mineira. Revista Brasileira de Milho e Sorgo, v.5, n.2, p.280-290, 2006.

TABILE, R.A.; TOLEDO, A.; SILVA, R.P.; FURLANI, C.E.A.; GROTTA, D.C.C.; CORTEZ, J.W. Perdas na colheita de milho em função da rotação do cilindro trilhador e umidade dos grãos. Scientia Agraria, v.9, n.4, p.505-510, 2008.

VENEGAS, F.; GASPARELLO, A.V.; ALMEIDA, M.P. Determinação de perdas na colheita mecanizada do milho (Zea mays L.) utilizando diferentes regulagens de rotação do cilindro trilhador da colheitadeira. Ensaios e Ciência: Ciências Biológicas, Agrárias e da Saúde, v.16, n.5, p. 43-55, 2012. 